\title{
Coccoloba uvifera (L.) (Polygonaceae) Fruit: Phytochemical Screening and Potential Antioxidant Activity
}

\author{
Maira Rubi Segura Campos, ${ }^{1}$ Jorge Ruiz Ruiz, ${ }^{2}$ \\ Luis Chel-Guerrero, ${ }^{1}$ and David Betancur Ancona ${ }^{1}$ \\ ${ }^{1}$ Facultad de Ingeniería Química, Universidad Autónoma de Yucatán, Periférico Norte km. 33.5, Tablaje Catastral 13615, \\ Colonia Chuburná de Hidalgo Inn, 97203 Mérida, YUC, Mexico \\ ${ }^{2}$ Departamento de Ingeniería Química-Bioquímica, Instituto Tecnológico de Mérida, Avenida Tecnológico km. $4.5 \mathrm{~S} / \mathrm{N}$, \\ 97118 Mérida, YUC, Mexico
}

Correspondence should be addressed to David Betancur Ancona; bancona@uady.mx

Received 31 July 2014; Revised 8 September 2014; Accepted 11 September 2014

Academic Editor: Dennis Fiorini

Copyright (C) 2015 Maira Rubi Segura Campos et al. This is an open access article distributed under the Creative Commons Attribution License, which permits unrestricted use, distribution, and reproduction in any medium, provided the original work is properly cited.

\begin{abstract}
The flora of Latin America attracts gaining interest as it provides a plethora of still unexplored or underutilized fruits that can contribute to human well-being due to their nutritional value and their content of bioactive compounds. Antioxidant compounds are now of considerable interest due to their effect of preventing or delaying aging and their apparent involvement in prevention of numerous human diseases, including cancer, atherosclerosis, Alzheimer's disease, inflammation, and rheumatoid arthritis. In this work, the fruit of Coccoloba uvifera (L.) was investigated for their in vitro antioxidant capacity using two assays based on reactions with a relatively stable single reagent radical (Trolox equivalent antioxidant capacity, TEAC; and DPPH free radical scavenging assay, DPPH), two assays based on chelating of metallic cations, and one based on the reduction of oxidized species. The TEAC value on ABTS radical, DPPH scavenging activity, ion chelation, and reducing power were found to be $897.6 \mu \mathrm{M}$ of Trolox/100 g of sample, $22.8 \%$ of DPPH free radical scavenging, $11.3 \%$ of $\mathrm{Cu}^{2+}$-chelating activity, $23.9 \%$ of $\mathrm{Fe}^{2+}$-chelating activity, and a $\mathrm{Fe}^{2+}$ reducing power of $0.76 \mathrm{mg} / \mathrm{mL}$, respectively. The free radical scavenging and antioxidant characteristics of $C$. uvifera may be due to the presence of diverse phytochemicals in the fruit as anthocyanins, ascorbic acid, phenolic compounds, and flavonoids.
\end{abstract}

\section{Introduction}

The importance of oxidation in the body and in foodstuffs has been widely recognized. Oxidative metabolism is essential for the survival of cells. Active oxygen and related species, superoxide anion $\left(\mathrm{O}_{2}{ }^{--}\right)$, hydroxyl radical $\left(\mathrm{OH}^{*}\right)$, nitric oxide $\left(\mathrm{NO}^{\circ}\right)$, hydrogen peroxide $\left(\mathrm{H}_{2} \mathrm{O}_{2}\right)$, lipid radical $\left(\mathrm{L}^{\circ}\right)$, lipid peroxyl radical $\left(\mathrm{LO}_{2}{ }^{\circ}\right)$, and lipid alkoxyl radical $\left(\mathrm{LO}^{\circ}\right)$, play a vital role in biological processes of energy production, phagocytosis, and signal transduction. There is increasing evidence to show that active oxygen species may also play a causative role in various diseases such as atherosclerosis, ischemia reperfusion injury, inflammation, carcinogenesis, cataracts, brain dysfunction, immune-system decline, cardiovascular disease, and rheumatoid arthritis $[1,2]$. Endogenous antioxidant enzymes, catalase, superoxide dismutase, and glutathione peroxidase defend against oxidative damage caused by active oxygen and related radicals. In addition to the enzymatic antioxidant defences, nutritional antioxidants in the diets may have protective effects to prevent oxidative stress related diseases. Low dietary intake of fruits and vegetables doubles the risk of most types of cancer as compared to high intake and also markedly increases the risk of heart disease and cataracts. In foods, it is recognized that lipid peroxidation causes deteriorations in food quality, unacceptable taste, and shortening of shelf-life. The antioxidant supplementation is a generally accepted method of prolonging the stability and storage life of food products, in particular the ones including fat. However, the artificial compounds with antioxidant properties, like butylated hydroxyanisole (BHA) and butylated hydroxytoluene (BHT), have a limited allowance for food due to their potential carcinogenicity [3]. 
One practical approach to solve this problem is the use of safer antioxidants from natural sources. Antioxidants are the substances able to prevent or inhibit oxidation processes in human body as well as in food products [1]. The natural antioxidants are a stable part of nutrition as they occur in almost all edible plant products. The phytochemicals are a large and diverse group of secondary metabolites that exhibit strong antioxidant activity in vitro. They are present in fruits and vegetables, their products, leguminous plants, grains, teas, herbs, spices, and wines [4]. Fruits and vegetables are high in components like ascorbic acid, phenols, flavonoid, and anthocyanin contents; it is estimated that humans consume between a few hundred milligrams and one gram of antioxidants every day [5]. Human studies have found too that these antioxidant components appear in blood plasma, at pharmacologically active levels, after eating certain foods but do not accumulate in the plasma [6]. Currently, increasing attention has been paid by consumers to the lesser known fruits which have unusual flavours and qualities and many of which are rich in antioxidants [7]. Detailed information about the health promoting components of lesser known fruits species could lead to a better understanding of the beneficial effects and an increased consumption of these fruits, including their utilization in functional foods and as ingredients in nutraceuticals, medicine, and pharmaceuticals [8]. C. uvifera is a species of flowering plant in the buckwheat family, Polygonaceae, which is native to coastal beaches throughout tropical America and the Caribbean, including southern Florida, the Bahamas, Barbados, and Bermuda. C. uvifera is a sprawling evergreen shrub or small tree that reaches a maximum height of $8 \mathrm{~m}$. In late summer it bears green fruit, about $2 \mathrm{~cm}$ diameters, in large grape-like clusters. The fruit gradually ripens to a purplish color. Each contains a large pit that constitutes most of the volume of the fruit [9]. Research on wild fruits and other wild edible plants is also intended to promote the preservation of these species, presently under threat by human activities. In addition to their nutritional value, the preservation of these fruits also has economic advantages, as there is a significant trade with some of this wild edible and medicinal fruits. Any scientific evidence for the health benefits of such wild fruits would be a value addition to the processing plants such fruits. This work will give a first appraisal of the characterization of primary compounds as well as the in vitro antioxidant activity of the C. uvifera fruit.

\section{Materials and Methods}

2.1. Chemicals, Raw Material, and Sampling. All reagents were of analytical grade. Ripe fruits of $C$. uvifera were collected in the coast of Yucatán, México. Fruits were botanically identified with the help of local flora [9]. The specimen (Code 2194) is deposited in the herbarium at the "Centro de Investigaciones Científicas de Yucatán, CICY," located in Yucatán, México. After reception, the fruits were selected, washed, and sanitized in chlorinated water and kept at $4^{\circ} \mathrm{C}$. Pulp obtaining was carried out in an extractor. The pulp was freeze-dried at $-47^{\circ} \mathrm{C}$ and $13 \times 10^{-3}$ mbar. Until analysis, the freeze-dried pulp was stored at $-20^{\circ} \mathrm{C}$.

2.2. Proximal Composition. Proximate composition was determined using AOAC [10] methods: moisture content (Method 925.09); ash (Method 923.03); crude fat (Method 920.39); crude protein, using a 6.25 nitrogen-protein conversion factor (Method 954.01); and crude fiber (Method 962.09). Carbohydrate content was estimated as nitrogen-free extract (NFE).

2.3. Determination of Total Titratable Acid (TTA). Determination of TTA was performed as described in AOAC standard method 942.15 with some modifications [10]. $1 \mathrm{~g}$ of lyophilized pulp was dissolved in $50 \mathrm{~mL}$ of distilled water. The titration was accomplished with $0.1 \mathrm{M} \mathrm{NaOH}$. After addition of several droplets of $\mathrm{NaOH}$ the $\mathrm{pH}$ value was recorded by using a $\mathrm{pH}$ meter. This procedure was repeated twice. The stoichiometric point was calculated and the results were expressed as citric acid equivalent.

\subsection{Quantification of Phytochemical Components}

2.4.1. Determination of Anthocyanins. Anthocyanins content was determined according to Salinas et al. [11]. One milliliter from the methanol extract was placed in a plastic cell for spectrophotometer and $2 \mathrm{~mL}$ of ethanol $96 \%-\mathrm{HCl} 1.0 \mathrm{~N}$ was added. A calibration curve was prepared using chlorinated pelargonidin $(10-50 \mathrm{mg} / \mathrm{mL})$, using extraction solution as blank. Absorbance was measured at a $520 \mathrm{~nm}$. The equation of the curve was used to calculate the concentration of anthocyanins in samples. The analysis was performed on three replicates. The total amount of anthocyanins was determined in micrograms of pelargonidin equivalents $(\mathrm{PE}) / 100 \mathrm{~g}$ of fruit weight.

2.4.2. Determination of Ascorbic Acid. Ascorbic acid content was determined according to the official AOAC method 967.21 [10]. Ten grams of fruit was mixed with $70 \mathrm{~mL}$ of cold extracting solution. This cold extracting solution consisted of $30 \mathrm{mg}$ of metaphosphoric acid, $80 \mathrm{~mL}$ of acetic acid, and distilled water added to $1000 \mathrm{~mL}$ and stored at $4^{\circ} \mathrm{C}$. The mixture was homogenized for $20 \mathrm{~min}$ at room temperature and then the solution was centrifuged at 9,000 $\mathrm{g}\left(\right.$ at $4^{\circ} \mathrm{C}$ ) for $20 \mathrm{~min}$. Several precautions were taken in order to perform all the operations under reduced light and at $4^{\circ} \mathrm{C}$. To quantify ascorbic acid content, ten milliliters of ascorbic acid extracts was titrated with 2,6-dichloroindophenol solution $(25 \mathrm{mg}$ DCIP and $21 \mathrm{mg} \mathrm{NaHCO}_{3}$ in $100 \mathrm{~mL}$ water) until light but distinct rose pink color appeared and persisted for more than 5 seconds. The 2,6-dichloroindophenol solution was standardized with ascorbic acid solution. All determinations were repeated three times and the results were expressed as $\mathrm{mg}$ ascorbic acid/100 $\mathrm{g}$ of fruit weight.

2.4.3. Determination of Total Phenolic. The phenolic compounds were determined using the Folin-Ciocalteu method, 
based on the reduction of phosphor-wolframate-phosphomolybdate complex by phenolics to a blue reaction product according to the method reported by Chaovanalikit and Wrolstad [12]. One g of sample was suspended in $40 \mathrm{~mL}$ of $80 \%$ methanol $(\mathrm{v} / \mathrm{v})$ in a beaker. The dispersion was stirred on a magnetic plate at room temperature for $3 \mathrm{~h}$. After the extraction the dispersion was centrifuged at $2500 \mathrm{rpm}$ for $20 \mathrm{~min}$ at $10^{\circ} \mathrm{C}$. The supernatant was filtered, refrigerated at $4^{\circ} \mathrm{C}$, and protected from light until analysis. A volume of $0.2 \mathrm{~mL}$ from the methanol extract was placed in a plastic cell for spectrophotometer and $0.2 \mathrm{~mL}$ of Folin-Ciocalteu reagent was added and homogenized. Then $2 \mathrm{~mL}$ of distilled water was added and the cell was kept in dark at room temperature for 1 hour. Absorbance was measured at $765 \mathrm{~nm}$. The data were calculated by comparison between a standard curve $(0-500 \mu \mathrm{g} / \mathrm{mL}$ of gallic acid) and the absorbance of each sample. The analysis was performed on three replicates. The total amount of phenolic compounds was determined in milligrams of gallic acid equivalents (GAE)/100 g of fruit weight.

2.4.4. Determination of Total Flavonoids. The flavonoids content was determined using the aluminum chloride method reported by Dewanto et al. [13]. Briefly, $0.5 \mathrm{~mL}$ from the ethanol extract was placed in a plastic cell for spectrophotometer; then $1.5 \mathrm{~mL}$ of ethanol $95 \%, 0.1 \mathrm{~mL} \mathrm{AlCl}_{3} 10 \%$, $0.1 \mathrm{~mL}$ of potassium acetate $1.0 \mathrm{M}$, and $2.8 \mathrm{~mL}$ of distilled water were added and the cell was kept in dark at room temperature for $30 \mathrm{~min}$. Absorbance was measured at $415 \mathrm{~nm}$. The data were calculated by comparison between a standard curve $(0-100 \mu \mathrm{g} / \mathrm{mL}$ of quercetin) and the absorbance of each sample. The analysis was performed on three replicates. The total amount of flavonoid compounds was determined in milligrams of quercetin equivalents $(\mathrm{QE}) / 100 \mathrm{~g}$ of fruit weigh.

\subsection{In Vitro Antioxidant Properties}

2.5.1. Trolox Equivalent Antioxidant Capacity. The ABTS ${ }^{*+}$ radical cation was produced by reacting 2,20-azino-bis (3ethylbenzothiazoline-6-sulphonic acid) (ABTS) with potassium persulfate [14]. To prepare the stock solution, ABTS was dissolved at a $2 \mathrm{mM}$ concentration in $50 \mathrm{~mL}$ phosphatebuffered saline (PBS) prepared from $4.0908 \mathrm{~g} \mathrm{NaCl}, 0.1347 \mathrm{~g}$ $\mathrm{KH}_{2} \mathrm{PO}_{4}, 0.7098 \mathrm{~g} \mathrm{Na}_{2} \mathrm{HPO}_{4}$, and $0.0749 \mathrm{~g} \mathrm{KCl}$ dissolved in $500 \mathrm{~mL}$ ultrapure water. If $\mathrm{pH}$ was lower than 7.4, it was adjusted with $\mathrm{NaOH}$. A $70 \mathrm{mM} \mathrm{K}_{2} \mathrm{~S}_{4} \mathrm{O}_{8}$ solution in ultrapure water was prepared. The ABTS radical cation was produced by reacting $10 \mathrm{~mL}$ ABTS stock solution with $40 \mu \mathrm{L} \mathrm{K}_{2} \mathrm{~S}_{2} \mathrm{O}_{8}$ solution and allowing the mixture to stand in darkness at room temperature for $16-17 \mathrm{~h}$ before use. The radical was stable in this form for more than 2 days when stored in darkness at room temperature. Antioxidant compound content in the sample was analyzed by diluting the ABTS ${ }^{*+}$ solution with PBS to an absorbance of $0.800+0.030 \mathrm{AU}$ at $734 \mathrm{~nm}$. After adding $990 \mathrm{~mL}$ diluted $\mathrm{ABTS}^{\circ+}$ solution (A $734 \mathrm{~nm}(1 / 4) 0.800+0.030)$ to $10 \mathrm{~mL}$ of 6-hydroxy-2,5,7,8tetramethylchroman-2-carboxylic acid (Trolox) standard in PBS, absorbance was read at room temperature exactly $6 \mathrm{~min}$ after initial mixing. All determinations were carried out in triplicate. The percentage decrease in absorbance at $734 \mathrm{~nm}$ was calculated and plotted as a function of the antioxidant concentration of Trolox for the standard reference data. To calculate the Trolox equivalent antioxidant coefficient (TEAC), the slope of the absorbance inhibition percentage versus antioxidant concentration plot was divided by the slope of the Trolox plot.

2.5.2. DPPH Free Radical Scavenging Assay. The scavenging effect on 1,1-diphenyl-2-picryl-hydrazyl (DPPH) free radical was measured as described by Shimada et al. [15]. With some modifications, a sample solution $(1.5 \mathrm{~mL})$ with $20 \mathrm{mg}$ was added to $1.5 \mathrm{~mL}$ of $0.1 \mathrm{mM}$ DPPH in $95 \%$ ethanol. The mixture was shaken and left for $30 \mathrm{~min}$ at room temperature. Absorbance was measured at $517 \mathrm{~nm}$. Measurement was performed at least in triplicate. The percentage of the DPPH free radical was calculated using the following equation: $\mathrm{DPPH}$ scavenging effect $(\%)=((\mathrm{A} 0-\mathrm{A} 1) / \mathrm{A} 0) \times 100$.

A0 was the absorbance of the control, where A1 was the absorbance in the presence of the C. uvifera pulp. The $\mathrm{IC}_{50}$ (concentration providing $50 \%$ inhibition) values were calculated using the dose inhibition curve in linear range by plotting the extract concentration versus the corresponding scavenging effect. Samples were tested in a range of concentrations from 2.0 to $10.0 \mathrm{mg} / \mathrm{mL}$.

2.5.3. Chelation of Metal Ions $\mathrm{Cu}^{2+}$ and $\mathrm{Fe}^{2+}$. $\mathrm{Cu}^{2+}$-chelating activity was determined using the pyrocatechol violet reagent according to Saiga et al. [16]. Briefly, $1.0 \mathrm{~mL}$ of sodium acetate buffer (100 mM, pH 4.9), $100 \mathrm{~mL}$ of $\mathrm{Cu}$ (II) standard solution $(1.0 \mathrm{mg} / \mathrm{mL}$ ), and $100 \mathrm{~mL}$ of sample (containing $200 \mu \mathrm{g}$ ) were mixed in a test tube. The mixture was allowed to react for $5 \mathrm{~min}$ at room temperature and $25 \mathrm{~mL}$ of a pyrocatechol violet solution $(4.0 \mathrm{mM})$ was then added. Absorbance was determined at $632 \mathrm{~nm}$. Copper chelating activity was calculated as follows: Chelating activity $(\%)=(1-$ sample A632/control A632) $\times 100 . \mathrm{Fe}^{2+}$-chelating activity was determined by measuring the formation of the $\mathrm{Fe}^{2+}$-ferrozine complex. Briefly, $1.0 \mathrm{~mL}$ of sodium acetate buffer $(100 \mathrm{mM}$, $\mathrm{pH} 4.9), 100 \mathrm{~mL}$ of $\mathrm{Fe}(\mathrm{II})$ standard solution $(1.0 \mathrm{mg} / \mathrm{mL})$, and $100 \mathrm{~mL}$ of sample (containing $200 \mathrm{mg}$ ) were mixed in a test tube. The mixture was allowed to react for $5 \mathrm{~min}$ at room temperature and $50 \mathrm{~mL}$ of a ferrozine solution $(40 \mathrm{mM})$ was then added. Absorbance was determined at $562 \mathrm{~nm}$. Iron chelating activity was calculated as follows: Chelating activity $(\%)=(1-$ sample A562/control A562 $) \times 100$.

2.5.4. Ferric Reducing Power Assay. This method is based on the reduction of potassium ferricyanide $\left(\mathrm{Fe}^{3+}\right)$ in the presence of an antioxidant to $\left(\mathrm{Fe}^{2+}\right)$ forming the blue complex $\mathrm{K}\left[\mathrm{Fe}^{\mathrm{II}}\left(\mathrm{CN}_{6}\right)\right]$, which is absorbed at $700 \mathrm{~nm}$ [17]. First, $200 \mathrm{~mL}$ of sample (containing $1 \mathrm{mg}$ ), $500 \mathrm{~mL}$ of phosphate buffer (0.2 M, pH 6.6), and $500 \mathrm{~mL}$ of potassium ferricyanide (1\%) were mixed in a test tube. The test tube was then incubated at $50^{\circ} \mathrm{C}$ for $20 \mathrm{~min}$. Subsequently, $500 \mathrm{~mL}$ of trichloroacetic acid $10 \%(\mathrm{w} / \mathrm{v})$ was added, and the tube was centrifuged at $3000 \times \mathrm{g}$ 
for $10 \mathrm{~min}$. An aliquot of $500 \mathrm{~mL}$ of the supernatant was dissolved in an equal amount of distilled water; immediately $500 \mathrm{~mL}$ of ferric chloride $(0.1 \%)$ was added. Absorbance was determined at $700 \mathrm{~nm}$. Samples were tested in a range of concentrations from 0.2 to $1.0 \mathrm{mg} / \mathrm{mL}$.

2.6. Statistical Analysis. All results were analyzed using descriptive statistics with a central tendency and dispersion measures. All analyses were done according to Montgomery [18] and processed with the Statgraphics Plus version 5.1 software.

\section{Results and Discussion}

3.1. Proximal Composition and Titratable Acidity (TTA). Generally fruits are not characterized by high protein content but the protein content of C. uvifera (Table 1) was higher than reported for other red fruits like black currants (Ribes rubrum) (0.6 g/100 g of sample) [19] or blackberries (Rubus fruticosus) (2 g/100 g of sample) [20].

C. uvifera showed a fat content of $1.82 \pm 0.27 \mathrm{~g} / 100 \mathrm{~g}$ of sample. This result is comparable to that of berries like blackberries, blueberries, or raspberries which generally contain $1 \%$ or less of fat [19]. C. uvifera fruits are found to be a good source of crude fibre. The determined content was $3.34 \mathrm{~g} \pm 0.46 \mathrm{~g} / 100 \mathrm{~g}$ of sample that is about twice the amount contained in guava (Psidium guajava L.) $(2.4 \mathrm{~g} / 100 \mathrm{~g}$ of sample) [21]. The fibre includes plant substances that resist the action of human digestive enzymes and is divided into two fractions: water-soluble (pectin, gum) and waterinsoluble (cellulose, lignin, and some of the hemicellulose). The latter is mainly credited for regulating bowl movement whereas the soluble fraction is chiefly involved in lowering blood cholesterol and glucose adsorption [21]. C. uvifera fruits are found to be a good source of carbohydrates $(86.59 \pm$ $0.59 \mathrm{~g} / 100 \mathrm{~g}$ of sample). Therefore, C. uvifera fruit pulp may be a valuable source of nutrients.

TTA of C. uvifera (Table 1) is comparable to that of ripe blackberries (5.78 equivalents of citric acid/100 $\mathrm{g}$ of fruit) [20]. The TTA is directly related to the organic acid content of the fruit. Organic acids are of great significance in plants as intermediates in the metabolic processes of the fruit; these acids are directly involved in growth, maturation, and senescence [22]. High values of TTA indicate that fruit is not ripe; on the contrary overripe fruits have very low levels of TTA. The state of maturity also influences the content of vitamins and phytochemicals related with the antioxidant properties of the fruit [23]. The TTA value obtained for the $C$. uvifera fruit pulp indicates that the fruit was processed in an adequate state of maturity, whereby the content of vitamins and phytochemicals may be the most appropriate to generate antioxidant activity.

\subsection{Quantification of Phytochemical Components}

3.2.1. Determination of Anthocyanins. The representative phenolic colorant anthocyanin is a subgroup of flavonoids that contain $\mathrm{C}_{3} \mathrm{C}_{6} \mathrm{C}_{3}$ carbon skeleton and cover a broad
TABLE 1: Centesimal specification of nutrients (dry weight) and titratable acidity of C. uvifera fruit.

\begin{tabular}{lc}
\hline Parameter & $(\mathrm{g} / 100$ of sample $)$ \\
\hline Protein & $3.96 \pm 0.48$ \\
Fat & $1.82 \pm 0.27$ \\
Crude fibre & $3.34 \pm 0.46$ \\
Ash & $4.29 \pm 0.36$ \\
Carbohydrates & $86.59 \pm 0.59$ \\
Titratable acidity & \\
Moisture & $5.9 \pm 0.11$ \\
\hline
\end{tabular}

${ }^{*}$ Expressed in citric acid equivalents.

range of colors including blue, purple, violet, magenta, red, and orange. Even though flavonoids release colors as well, anthocyanins are the most broadly distributed pigment in the plant world [24]. Anthocyanins differ in the number of hydroxyl and/or methoxy groups present and sugars such as glucose, galactose, arabinose, and xylose are attached to the 3 positions in the $\mathrm{C}$ ring [25]. Anthocyanins are involved in a wide range of biological activities and may affect positively the health. Many of the biological properties are closely associated with the antioxidant activity of anthocyanin pigments [26]. Antioxidative properties of anthocyanins arise from their high reactivity as hydrogen or electron donors, from the ability of the polyphenol-derived radicals to stabilize and delocalize the unpaired electron, and from their ability to chelate transition metal ions [24]. Total anthocyanin content in C. uvifera pulp fruit was measured using a spectrometric method. An aliquot of sample was properly diluted into a spectrometric linear range for chlorinated pelargonidin $(10-50 \mathrm{mg} / \mathrm{mL})$, using extraction solution as blank. Anthocyanin content of C. uvifera pulp fruit was reported as $\mu \mathrm{g}$ of pelargonidin equivalents $/ 100 \mathrm{~g}$ of fruit weight (Table 2). The content of anthocyanins of C. uvifera fruit pulp is comparable to that of strawberry $(24.0 \mathrm{mg} / 100 \mathrm{~g})$ [27]. It has been estimated that daily ingest of anthocyanins is $12.5 \mathrm{mg}$ and anthocyanin remains intact when passing from the digestive tract to the blood circulation of mammals [6]. This is extremely important considering that anthocyanins not only act as antioxidants but also reduce the risk of coronary heart disease, inhibit platelet aggregation, and protect arterial endothelial cells. In addition, these pigments could decrease the risk of cancer, reduce inflammatory process, and modulate immune response [28]. The obtained results indicated that the fruit of $C$. uvifera could be considered a good source of dietary anthocyanins.

3.2.2. Determination of Ascorbic Acid. Ascorbic acid (vitamin $\mathrm{C}$ or ascorbate) is a six-carbon lactone that is synthesized from glucose by many animals. However, humans are unable to synthesize vitamin $\mathrm{C}$. When there is insufficient vitamin $\mathrm{C}$ in the diet, humans suffer from the potentially lethal deficiency disease scurvy. More than $90 \%$ of the vitamin C in human diets is supplied by fruits and vegetables [29]. Ascorbic acid is an electron donor (reducing agent or antioxidant), and probably all of its biochemical and molecular functions 
TABLE 2: Phytochemical components of C. uvifera fruit.

\begin{tabular}{lc}
\hline Phytochemical component & Value \\
\hline Anthocyanins (mg of pelargonidin equivalents/100 g of fruit weight) & $32.94 \pm 3.29$ \\
Ascorbic acid (mg of ascorbic acid equivalents/100 g of fruit weight) & $6.25 \pm 0.87$ \\
Total phenolic compounds (mg of gallic acid equivalents/100 $\mathrm{g}$ of fruit weight) & $177.23 \pm 9.45$ \\
Total flavonoids compounds (mg of quercetin equivalents/100 $\mathrm{g}$ of fruit weight) & $9.67 \pm 1.12$ \\
\hline
\end{tabular}

can be accounted for by this function. Ascorbic acid acts on the one hand as an important water-soluble antioxidant in biological fluids by scavenging physiologically relevant reactive oxygen species. In addition to this direct antiradical capacity, ascorbic acid is able to regenerate other antioxidants like $\alpha$-tocopherol, glutathione, urate, and $\beta$-carotene from their respective radical species. On the other hand, ascorbic acid exerts also regulatory functions on a cellular level by influencing gene expression and apoptosis and can act as a cofactor maintaining the activity of a number of enzymes by keeping metal ions in the reduced state [30]. The ascorbic acid content of $C$. uvifera pulp fruit was determined by titrimetric method using 2,6-dichloroindophenol and reported as ascorbic acid/100 $\mathrm{g}$ of fruit by reference to a standard ascorbic acid solution (Table 2). The C. uvifera fruit content of ascorbic acid was comparable to that of apple "green" $(6.0 \mathrm{mg} / 100 \mathrm{~g})$, banana (3.1 mg/100 g), coconut (3.3 mg GAE/100 g), and water melon "light green" (6.8 mg/100 g) [31]. The obtained results indicated that the content of ascorbic acid of the $C$. uvifera fruit is relatively low. However the consumption of fruits is beneficial and the health effects are ascribed in part to ascorbic acid content [32]. Ascorbic acid is a powerful antioxidant because it can donate a hydrogen atom and form a relatively stable ascorbyl free radical. The ascorbyl free radical can be converted back to reduce ascorbate by accepting another hydrogen atom or it can undergo further oxidation to dehydroascorbate. Dehydroascorbate is unstable but is more fat soluble than ascorbate and is taken up 10-20 times more rapidly by erythrocytes, where it will be reduced back to ascorbate by NADPH from the hexose monophosphate shunt; thus mechanisms exist to recycle vitamin $\mathrm{C}$ in human organism [29]. Therefore it is important to consider the contribution of ascorbic acid in the antioxidant activity of $C$. uvifera fruit.

\subsubsection{Determination of Total Phenolic. Phenolic compounds} are commonly found in both edible and inedible plants and have been reported to have multiple biological effects, including antioxidant activity. Phenolics are able to scavenge reactive oxygen species due to their electron donating properties. Their antioxidant effectiveness depends on the stability in different systems, as well as number and location of hydroxyl groups [33]. The total phenolic content of C. uvifera pulp fruit was determined using Folin-Ciocalteu method and reported as gallic acid equivalents by reference to standard curve (Table 2). The amount of extractable polyphenols varied greatly among the fruit species. According to Vasco et al. [34], fruits can be classified into three categories by their polyphenol content: low (<100 mg GAE/100 g), medium (100-500 mg GAE/100 g), and high (>500 mg GAE/100 g). According to the above classification the $C$. uvifera pulp fruit would be classified with a medium content of polyphenols comparable to that of apple "Gala" (132 mg GAE/100 g), orange (217 mg GAE/100 g), kiwi fruit (273 mg GAE/100 g), and pink grapefruit (425 mg GAE/100 g). Polyphenol supply for the human organism is affected, not only by their concentrations in the raw material, but also by the amount of consumption. Besides, these compounds are more active in human organism in the presence of vitamin C. It is also thought that polyphenols present in fruit have stronger effects because saccharides enhance their assimilation. Saccharides bound to polyphenols act as hydrogen ligands in hydroxyl groups of these compounds. As antioxidants, dietary polyphenols may protect cell constituents against oxidative damage and, therefore, limit the risk of various degenerative diseases associated with oxidative stress. Numerous studies on animal models have shown that, when added to the diet, they limit the development of cancers, cardiovascular diseases, neurodegenerative diseases, diabetes, and osteoporosis [35]. The obtained results indicated that the fruit of $C$. uvifera could be considered as a good source of dietary polyphenols.

3.2.4. Determination of Total Flavonoids. Flavonoids are a broad class of low molecular weight, secondary plant phenolics characterized by the flavan nucleus. In plants, these compounds afford protection against ultraviolet radiation, pathogens, and herbivores [36]. Most of the beneficial health effects of flavonoids are attributed to their antioxidant and chelating abilities. By virtue of their capacity to inhibit LDL oxidation, flavonoids have demonstrated unique cardioprotective effects [37]. A protective role in the diet of humans has also been indicated in some large, prospective studies. For example, high flavonoid intake predicted lower mortality from coronary heart disease and lower incidence of myocardial infarction in older men and reduced the risk of coronary heart disease by $38 \%$ in postmenopausal women. The Zutphen Elderly Study demonstrated an inverse relationship between consumption of catechin, a predominant flavonoid in tea, and ischemic heart disease mortality in a cohort of 806 men [38]. The protective effects of flavonoids in biological systems are ascribed to their capacity to transfer electrons free radicals, chelate metal catalysts, activate antioxidant enzymes, reduce alpha-tocopherol radicals, and inhibit oxidases [39]. The total flavonoids content of $C$. uvifera pulp fruit was determined using the aluminum chloride method and 
TABLE 3: Antioxidant properties of C. uvifera fruit pulp compared with standard antioxidants.

\begin{tabular}{|c|c|c|c|}
\hline Parameter & C. uvifera & Trolox [49] & BHT $^{*}[49]$ \\
\hline TEAC ( $\mu \mathrm{M}$ of Trolox/100 g of sample) & $897.6 \pm 22.8$ & $\mathrm{IC}_{50}=2.08 \mu \mathrm{g} / \mathrm{mL}$ & $\mathrm{IC}_{50}=1.66 \mu \mathrm{g} / \mathrm{mL}$ \\
\hline DPPH (\% of free radical scavenging) & $22.8 \pm 0.44$ & 48 & 55 \\
\hline $\mathrm{IC}_{50}(\mu \mathrm{g} / \mathrm{mL})$ & $4.4 \pm 0.87$ & 5.28 & 1.66 \\
\hline $\mathrm{Cu}^{2+}$-chelating activity ( $\%$ of chelating activity) & $11.3 \pm 0.65$ & 34 & 6 \\
\hline $\mathrm{Fe}^{2+}$-chelating activity (\% of chelating activity) & $23.9 \pm 0.51$ & 14 & 11 \\
\hline Ferric reducing power, $\mathrm{IC}_{50}(\mu \mathrm{g} / \mathrm{mL})$ & $760 \pm 4.0$ & 19.04 & 20.62 \\
\hline
\end{tabular}

${ }^{*}$ Butylated hydroxytoluene.

the total amount of flavonoid compounds was determined in milligrams of quercetin equivalents $(\mathrm{QE}) / 100 \mathrm{~g}$ of fruit weight (Table 2). The C. uvifera fruit content of total flavonoids was comparable to that of apple $(7.0 \mathrm{mg} / 100 \mathrm{~g})$, black currant $(6.8 \mathrm{mg} / 100 \mathrm{~g})$, and elderberry (10.5 mg GAE/100 g) [40]. It is now widely accepted that dietary flavonoids may play an important role in protecting the body against chronic diseases, such as cancer, cardiovascular diseases, and diabetes mellitus [41]. The obtained results indicated C. uvifera fruit is a good source of dietary flavonoids.

3.3. Antioxidant Properties. Several methods have been developed for the assessment of the antioxidant efficiency. Because many active species and reaction mechanisms are involved in oxidative stress process; no simple universal method can be applied for accurate and quantitative measurement of antioxidant capacity [42]. Generally, in these methods a radical is generated and the antioxidant capability of a sample against the radical is evaluated. In the present study, the antioxidant activity of the C. uvifera fruit pulp was determined using ABTS and DPPH radical scavenging assays, metal chelating assay, and ferric reducing antioxidant power assay.

3.3.1. Trolox Equivalent Antioxidant Capacity. The ABTS assay is based on the inhibition by antioxidants of the absorbance of the radical cation ABTS ${ }^{\bullet+}$. The use of Trolox as a standard allows the assay to be called Trolox equivalent antioxidant capacity (TEAC). ABTS assay is an excellent tool for determining the antioxidant activity of hydrogendonating antioxidants and of chain-breaking antioxidants [43]. The radical cation $\mathrm{ABTS}^{\circ+}$ is soluble in aqueous and organic solvents, making the assay a suitable method for determining the hydrophilic and lipophilic antioxidant capacity of extracts and biological fluids [44]. The C. uvifera fruit pulp efficiently scavenged ABTS radicals generated by the reaction between $2,2^{\prime}$-azinobis (3-ethylbenzothiazoline6-sulphonic acid) (ABTS) and potassium persulfate (Table 3).

The ABTS radical scavenging activity of C. uvifera $(897.6 \mu \mathrm{M}$ of Trolox/100 g) is comparable to that of other fruits like guava (Psidium guajava) $(820 \mu \mathrm{M}$ of Trolox/100 g), grape (Vitis vinifera) $(920 \mu \mathrm{M}$ of Trolox/100), or Acai (Euterpe oleracea) $(940 \mu \mathrm{M}$ of Trolox/100 g) [45].

3.3.2. DPPH Free Radical Scavenging Assay. The radical DPPH has the advantage of being unaffected by certain

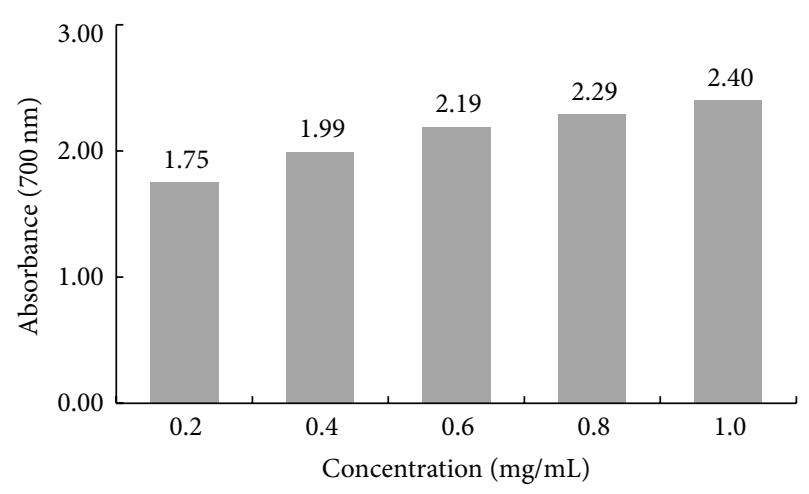

FIGURE 1: Ferric reducing power of C. uvifera fruit pulp.

side reactions, such as metal ion chelation and enzyme inhibition, brought about by various additives. A freshly prepared DPPH solution exhibits a deep purple color with a maximum absorption at $517 \mathrm{~nm}$. This purple color generally fades/disappears when an antioxidant is present in the medium. Thus, antioxidant molecules can quench DPPH free radicals (i.e., by providing hydrogen atoms or by electron donation, conceivably via a free radical attack on the DPPH molecule) and convert them to a colorless/bleached product, DPPH-H (i.e., 2,2-diphenyl-1-hydrazine or a substituted analogous hydrazine), resulting in a decrease in absorbance at $517 \mathrm{~nm}$ [46]. It is also important to note that the DPPH test only recognizes free radical scavenging effects and not prooxidant activity. The percentage of DPPH radical scavenging of the C. uvifera (22.8\%) is showed in Table 3. It has been found that cysteine, glutathione, ascorbic acid, tocopherol, polyhydroxy aromatic compound reduce and decolorize DPPH by their hydrogen donating ability. It appears that C. uvifera possesses hydrogen donating abilities to act as an antioxidant. Surinrut et al. [47] reported high antioxidant activity $\left(\mathrm{IC}_{50}\right.$ from 1.1-9.6 $\mu \mathrm{g} / \mathrm{mL}$ ) in fruits like mulberries (Morus rubra), mango (Mangifera indica), carambola (Averrhoa carambola), and guava (Psidium guajava). The DPPH radical scavenging $\mathrm{IC}_{50}(4.4 \mu \mathrm{g} / \mathrm{mL})$ of C. uvifera pulp is comparable to that of other fruits.

3.3.3. Chelation of Metal Ions $\mathrm{Cu}^{2+}$ and $\mathrm{Fe}^{2+}$. Metal ion chelating activity of an antioxidant molecule prevents oxyradical generation and the consequent oxidative damage. Metal ion chelating capacity plays a significant role in 
antioxidant mechanisms, since it reduces the concentration of the catalyzing transition metal in lipid peroxidation. At a concentration of $0.2 \mathrm{mg} / \mathrm{mL}$, the C. uvifera lyophilized juice exhibits chelating effects of $11.3 \%$ and $23.9 \%$, for $\mathrm{Cu}^{2+}$ and $\mathrm{Fe}^{2+}$, respectively. It was confirmed in numerous studies that, in addition to direct free radical scavenging, flavonoids exert antioxidant activity through interactions with the reduced form of transition metals, primarily $\mathrm{Fe}(\mathrm{II}), \mathrm{Fe}(\mathrm{III})$, and $\mathrm{Cu}(\mathrm{I})$, which participate in reactions generating free radicals [48]. The results of the present study suggest that the C. uvifera fruit pulp exhibits chelation activity on cuprous and ferrous ions probably due to their content of flavonoids.

3.3.4. Ferric Reducing Power Assay. The reducing power of a compound is related to its electron transfer ability and may serve as a significant indicator of its potential antioxidant activity. In this assay, the yellow color of the test solution changes to green and blue depending on the reducing power of test specimen. Greater absorbance at $700 \mathrm{~nm}$ indicated greater reducing power. Figure 1 presents the reductive capabilities of the $C$. uvifera juice. In the concentration range investigated, the lyophilized juice demonstrated reducing power that increased linearly with concentration. At $0.4,0.8$, $1.2,1.6$, and $2.0 \mathrm{mg} / \mathrm{mL}$, reducing power of C. uvifera pulp were found to be $1.75,1.99,2.19,2.29$, and 2.40 , respectively. The $\mathrm{IC}_{50}$ value was found to be $0.76 \mathrm{mg} / \mathrm{mL}(760 \mu / \mathrm{mL})$. The reducing power of the $C$. uvifera pulp might be due to their hydrogen donating ability.

The beneficial effects of fruits are attributed largely to substances proven to be effective free radical scavenging and having antioxidant properties, such as anthocyanins [11], ascorbic acid, polyphenolic [12], and flavonoid [13] compounds. At this point it is good to recall the difference between an antioxidant and a radical scavenger, as often these terms are both used in antioxidant literature. In principle, any radical scavenger can be an antioxidant if it terminates radical chain propagation. Radical scavengers are the largest class of antioxidants. In addition antioxidant classes such as metal chelators, oxygen scavengers, UV light absorbers, and enzymatic antioxidants are recognized. Possibly, C. uvifera fruit pulp contains high amounts of phytochemicals, which could react with radicals to stabilize and terminate radical chain reactions.

\section{Conclusion}

Primary compounds, phytochemicals, and antioxidant properties of $C$. uvifera fruit pulp are being reported here for the first time. This fruit is a good source of nutrients and shows in vitro antioxidant properties comparable to those of conventional fruits. The antioxidant effects appeared to be due to the contents phytochemicals like polyphenols, flavonoids, anthocyanins, and ascorbic acid. Total phenolic compounds in C. uvifera fruit pulp seemed to be the major contributors. Mexico is one of the countries that have a rich diversity of underutilized fruits that grow wild in the region of Yucatan Peninsula. Some of the underutilized fruits are rarely eaten, unknown, and unfamiliar. However, underutilized fruits have not received much attention as antioxidant sources compared to commercial fruits like guava, papaya, and pineapple. This could be due to their lack of popularity among local communities, lack of information on nutritional compositions and physical qualities, and the lack of promotional campaign for these fruits. This research improves the knowledge of plants from Mexico and will promote their appreciation, although more studies must be carried out to identify and quantify the phytochemicals associated with their antioxidant activity.

\section{Conflict of Interests}

The authors declare that there is no conflict of interests regarding the publication of this paper.

\section{References}

[1] K. B. Pandey and S. I. Rizvi, "Plant polyphenols as dietary antioxidants in human health and disease," Oxidative Medicine and Cellular Longevity, vol. 2, no. 5, pp. 270-278, 2009.

[2] A. Siger, J. Czubinski, P. Kachlicki, K. Dwiecki, E. LampartSzczapa, and M. Nogala-Kalucka, "Antioxidant activity and phenolic content in three lupin species," Journal of Food Composition and Analysis, vol. 25, no. 2, pp. 190-197, 2012.

[3] Y. Zhao, S.-K. Du, H. Wang, and M. Cai, "In vitro antioxidant activity of extracts from common legumes," Food Chemistry, vol. 152, pp. 462-466, 2014.

[4] A. Duda-Chodak and T. Tarko, "Antioxidant properties of different fruit seeds and peels," Acta Scientiarum Polonorum. Technologia Alimentaria, vol. 6, no. 3, pp. 29-36, 2007.

[5] A. Al-Farga, Z. Hui, and S. Azhari, "In vitro antioxidant activity and total phenolic and flavonoid contents of Alhydwan (Boerhavia elegana Choisy) seeds," Journal of Food and Nutrition Research, vol. 2, no. 5, pp. 215-220, 2014.

[6] C. Fredes, G. Montenegro, J. P. Zoffoli, F. Santander, and P. Paz Robert, "Comparison of the total phenolic content, total anthocyanin content and antioxidant activity of polyphenolrich fruits grown in Chile," Ciencia e Investigacion Agraria, vol. 41, no. 1, pp. 49-59, 2014.

[7] J. A. Ozga, A. Saeed, W. Wismer, and D. M. Reinecke, "Characterization of cyanidin- and quercetin-derived flavonoids and other phenolics in mature saskatoon fruits (Amelanchier alnifolia Nutt.)," Journal of Agricultural and Food Chemistry, vol. 55, no. 25, pp. 10414-10424, 2007.

[8] K. U. Yilmaz, S. Ercisli, Y. Zengin, M. Sengul, and E. Y. Kafkas, "Preliminary characterisation of cornelian cherry (Cornus mas L.) genotypes for their physico-chemical properties," Food Chemistry, vol. 114, no. 2, pp. 408-412, 2009.

[9] F. Maldonado-Mares, Frutales Tropicales de Tabasco, Universidad Juárez Autónoma de Tabasco, Tabasco, Mexico, 2004.

[10] AOAC, Official Methods of Analysis, Association of Official Analytical Chemist, Arlington, Va, USA, 6th edition, 1998.

[11] Y. Salinas, F. J. Cruz, S. A. Díaz, and F. Castillo, "Pigmented maize grains fromchiapas, physical characteristics, anthocyanin content and nutraceutical value," Revista Fitotecnia Mexicana, vol. 35, no. 1, pp. 33-41, 2012.

[12] A. Chaovanalikit and R. E. Wrolstad, "Total anthocyanins and total phenolics of fresh and processed cherries and their antioxidant properties," Journal of Food Science, vol. 69, no. 1, pp. FCT67-FCT72, 2004. 
[13] V. Dewanto, W. Xianzhong, K. K. Adom, and R. H. Liu, "Thermal processing enhances the nutritional value of tomatoes by increasing total antioxidant activity," Journal of Agricultural and Food Chemistry, vol. 50, no. 10, pp. 3010-3014, 2002.

[14] A. Pukalskas, T. A. van Beek, R. P. Venskutonis, J. P. H. Linssen, A. Van Veldhuizen, and D. De Groot, "Identification of radical scavengers in sweet grass (Hierochloe odorata)," Journal of Agricultural and Food Chemistry, vol. 50, no. 10, pp. 2914-2919, 2002.

[15] K. Shimada, K. Fujikawa, K. Yahara, and T. Nakamura, "Antioxidative properties of xanthan on the autoxidation of soybean oil in cyclodextrin emulsion," Journal of Agricultural and Food Chemistry, vol. 40, no. 6, pp. 945-948, 1992.

[16] A. Saiga, S. Tanabe, and T. Nishimura, "Antioxidant activity of peptides obtained from porcine myofibrillar proteins by protease treatment," Journal of Agricultural and Food Chemistry, vol. 51, no. 12, pp. 3661-3667, 2003.

[17] G.-C. Yen and H.-Y. Chen, "Antioxidant activity of various tea extracts in relation to their antimutagenicity," Journal of Agricultural and Food Chemistry, vol. 43, no. 1, pp. 27-32, 1995.

[18] D. Montgomery, Diseño y Análisis de Experimentos, Limusa Wiley, Mexico DF, Mexico, 2004.

[19] A. Gordon, B. Schadow, C. E. Quijano, and F. Marx, "Chemical characterization and antioxidant capacity of berries from Clidemia rubra (Aubl.) Mart. (Melastomataceae)," Food Research International, vol. 44, no. 7, pp. 2120-2127, 2011.

[20] I. Tosun, N. S. Ustun, and B. Tekguler, "Physical and chemical changes during ripening of blackberry fruits," Scientia Agricola, vol. 65, no. 1, pp. 87-90, 2008.

[21] O. A. Ashaye, S. O. Babalola, A. O. Babalola, J. O. Aina, and S. B. Fasoyiro, "Chemical and organoleptic characterization of Pawpaw and Guava leathers," World Journal of Agricultural Sciences, vol. 1, no. 1, pp. 50-51, 2005.

[22] P. Perkins-Veazie, J. R. Clark, D. J. Huber, and E. A. Baldwin, "Ripening physiology in "Navaho" thornless blackberries: color, respiration, ethylene production, softening, and compositional changes," Journal of the American Society for Horticultural Science, vol. 125, no. 3, pp. 357-363, 2000.

[23] V. Akbarpour, K. Hemmati, and M. Sharifani, "Physical and chemical properties of pomegranate (Punica granatum L.) fruit in maturation stage," American-Eurasian Journal of Agriculture and Environmental Science, vol. 6, no. 4, pp. 411-416, 2009.

[24] G. Skrede and R. Wrolstad, "Flavanoids from beries and grapes," in Functional Foods: Biochemical and Processing Aspects, J. Shi, G. Mazza, M. Le Maguer, and R. Boca, Eds., vol. 2, p. 71, CRC Press, Boca Raton, Fla, USA, 2002.

[25] Q. Du, J. Zheng, and Y. Xu, "Composition of anthocyanins in mulberry and their antioxidant activity," Journal of Food Composition and Analysis, vol. 21, no. 5, pp. 390-395, 2008.

[26] J.-M. Kong, L.-S. Chia, N.-K. Goh, T.-F. Chia, and R. Brouillard, "Analysis and biological activities of anthocyanins," Phytochemistry, vol. 64, no. 5, pp. 923-933, 2003.

[27] Y. Zheng, S. Y. Wang, C. Y. Wang, and W. Zheng, "Changes in strawberry phenolics, anthocyanins, and antioxidant capacity in response to high oxygen treatments," LWT-Food Science and Technology, vol. 40, no. 1, pp. 49-57, 2007.

[28] A. M. M. Basuny, S. M. Arafat, and M. A. El-Marzooq, "Antioxidant and antihyperlipidemic activities of anthocyanins from eggplant peels," Journal of Pharma Research \& Reviews, vol. 2, no. 3, pp. 50-57, 2012.
[29] K. Shrivas, K. Agrawal, and D. K. Patel, "A spectrophotometric determination of ascor bic acid," Journal of the Chinese Chemical Society, vol. 52, no. 3, pp. 503-506, 2005.

[30] C. Balsano and A. Alisi, "Antioxidant effects of natural bioactive compounds," Current Pharmaceutical Design, vol. 15, no. 26, pp. 3063-3073, 2009.

[31] W. Okiei, M. Ogunlesi, L. Azeez, V. Obakachi, M. Osunsanmi, and G. Nkenchor, "The voltammetric and titrimetric determination of ascorbic acid levels in tropical fruit samples," International Journal of Electrochemical Science, vol. 4, no. 2, pp. 276-287, 2009.

[32] C. Rekha, G. Poornima, M. Manasa et al., "Ascorbic acid, total phenol content and antioxidant activity of fresh juices of four ripe and unripe citrus fruits," Chemical Science Transactions, vol. 1, no. 2, pp. 303-310, 2012.

[33] A. Podsedek, "Natural antioxidants and antioxidant capacity of Brassica vegetables: a review," LWT: Food Science and Technology, vol. 40, no. 1, pp. 1-11, 2007.

[34] C. Vasco, J. Ruales, and A. Kamal-Eldin, "Total phenolic compounds and antioxidant capacities of major fruits from Ecuador," Food Chemistry, vol. 111, no. 4, pp. 816-823, 2008.

[35] A. Scalbert, C. Manach, C. Morand, C. Rémésy, and L. Jiménez, "Dietary polyphenols and the prevention of diseases," Critical Reviews in Food Science and Nutrition, vol. 45, no. 4, pp. 287306, 2005.

[36] J. B. Harborne and C. A. Williams, "Advances in flavonoid research since 1992," Phytochemistry, vol. 55, no. 6, pp. 481-504, 2000.

[37] A. Mazur, D. Bayle, C. Lab, E. Rock, and Y. Rayssiguier, "Inhibitory effect of procyanidin-rich extracts on LDL oxidation in vitro," Atherosclerosis, vol. 145, no. 2, pp. 421-422, 1999.

[38] I. C. W. Arts, P. C. H. Hollman, E. J. M. Feskens, H. B. Bueno de Mesquita, and D. Kromhout, "Catechin intake might explain the inverse relation between tea consumption and ischemic heart disease: the Zutphen Elderly Study," The American Journal of Clinical Nutrition, vol. 74, no. 2, pp. 227-232, 2001.

[39] R. Hirano, W. Sasamoto, A. Matsumoto, H. Itakura, O. Igarashi, and K. Kondo, "Antioxidant ability of various flavonoids against DPPH radicals and LDL oxidation," Journal of Nutritional Science and Vitaminology, vol. 47, no. 5, pp. 357-362, 2001.

[40] S. A. Aherne and N. M. O’Brien, "Dietary flavonols: chemistry, food content, and metabolism," Nutrition, vol. 18, no. 1, pp. 75$81,2002$.

[41] P. Knekt, J. Kumpulainen, R. Järvinen et al., "Flavonoid intake and risk of chronic diseases," The American Journal of Clinical Nutrition, vol. 76, no. 3, pp. 560-568, 2002.

[42] E. N. Frankel and J. W. Finley, "How to standardize the multiplicity of methods to evaluate natural antioxidants," Journal of Agricultural and Food Chemistry, vol. 56, no. 13, pp. 4901-4908, 2008.

[43] L. P. Leong and G. Shui, "An investigation of antioxidant capacity of fruits in Singapore markets," Food Chemistry, vol. 76, no. 1, pp. 69-75, 2002.

[44] R. L. Prior, X. Wu, and K. Schaich, "Standardized methods for the determination of antioxidant capacity and phenolics in foods and dietary supplements," Journal of Agricultural and Food Chemistry, vol. 53, no. 10, pp. 4290-4302, 2005.

[45] E. M. Kuskoski, A. G. Asuero, A. M. Troncoco, J. ManciniFilho, and R. Roseane Fett, "Aplicación de diversos métodos químicos para determinar actividad antioxidante en pulpa de frutos," Ciencia y Tecnología Alimentaria, vol. 25, no. 4, pp. 726732, 2005. 
[46] A. M. Pisoschi, M. C. Cheregi, and A. F. Danet, "Total antioxidant capacity of some commercial fruit juices: electrochemical and spectrophotometrical approaches," Molecules, vol. 14, no. 1, pp. 480-493, 2009.

[47] P. Surinrut, S. Kaewsutthi, and R. Surakarnkul, "Radical scavenging activity in fruit extracts," in Proceedings of the WOCMAP III, Vol. 5: Quality, Efficacy, Safety, Processing \& Trade in MAPs, E. Brovelli, S. Chansakaow, D. Farias et al., Eds., vol. 5, ISHS, 2005.

[48] M. Y. Moridani, J. Pourahmad, H. Bui, A. Siraki, and P. J. O'Brien, "Dietary flavonoid iron complexes as cytoprotective superoxide radical scavengers," Free Radical Biology and Medicine, vol. 34, no. 2, pp. 243-253, 2003.

[49] X. Li, X. Wang, D. Chen, and S. Chen, "Antioxidant activity and mechanism of protocatechuic acid in vitro," Functional Foods in Health and Disease, vol. 7, pp. 232-244, 2011. 

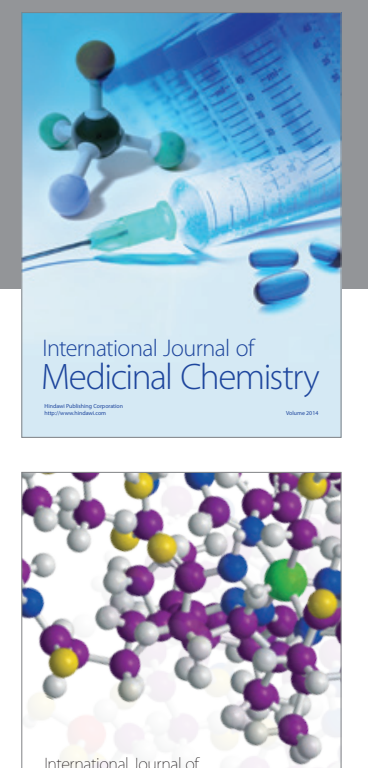

\section{Carbohydrate} Chemistry

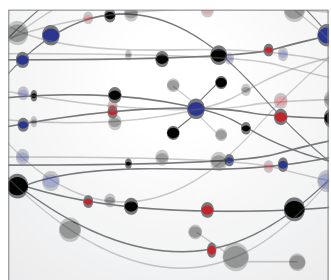

The Scientific World Journal
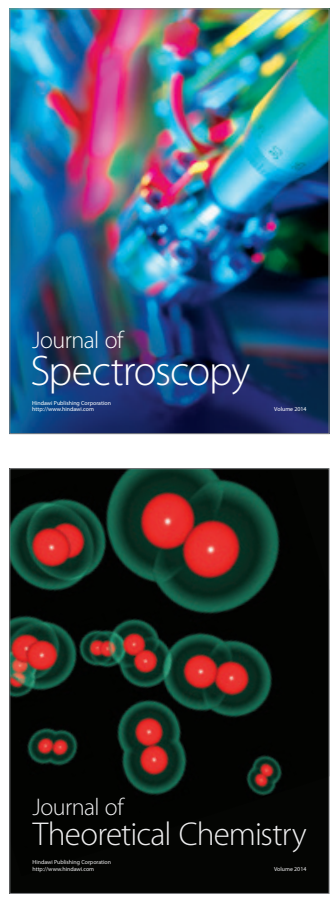
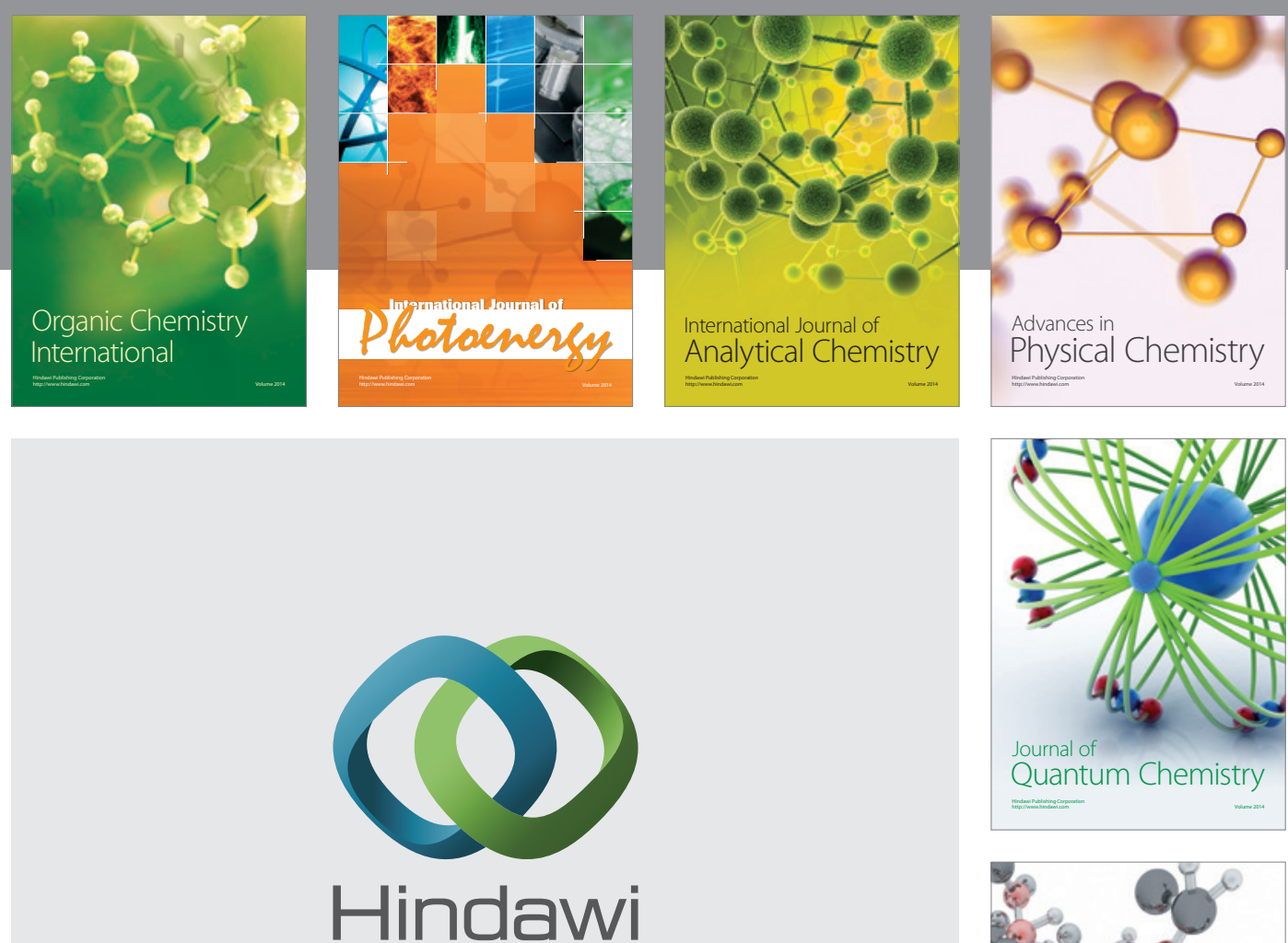

Submit your manuscripts at

http://www.hindawi.com

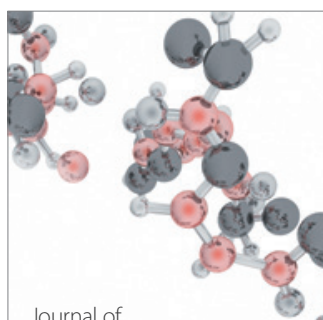

Analytical Methods

in Chemistry

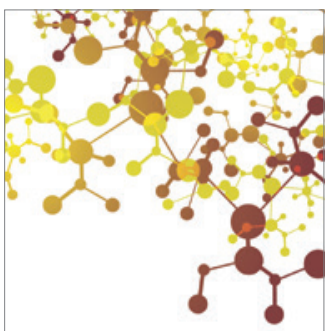

Journal of

Applied Chemistry

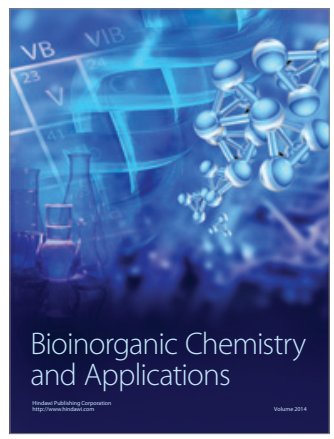

Inorganic Chemistry
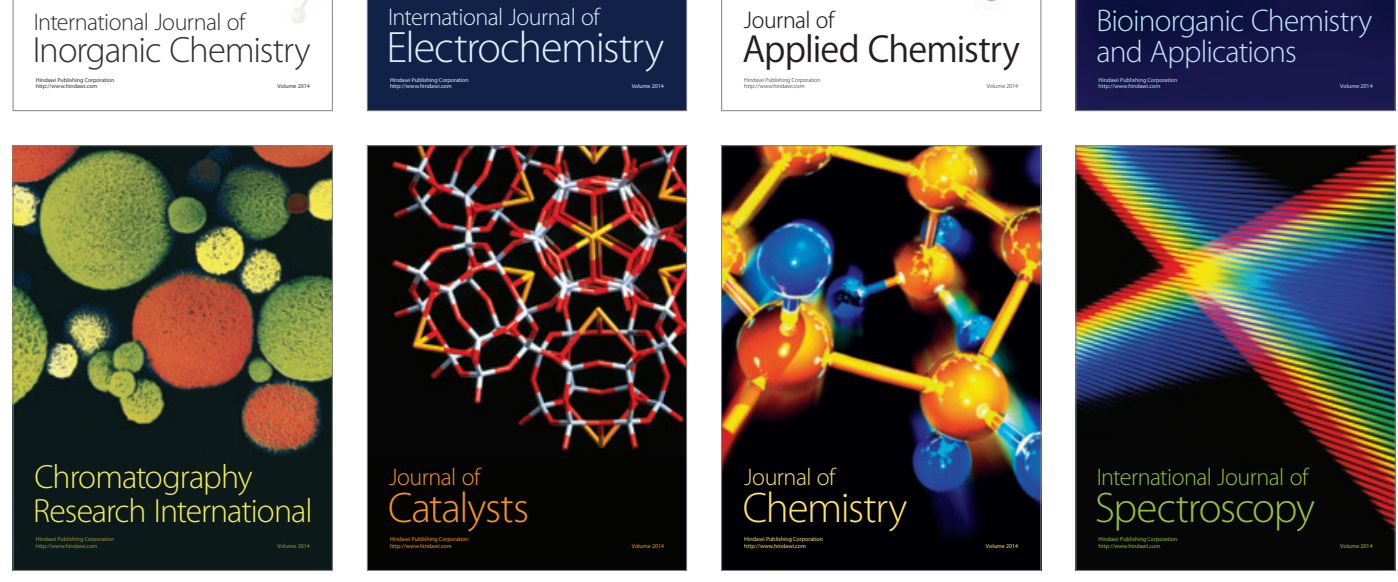